\title{
FOOD AND FEEDING BEHAVIOUR OF HYLA ANNECTANS (JERDON, 1870) IN NAGALAND, INDIA
}

\author{
Meren Ao ${ }^{1}$, Sabitry Bordoloi ${ }^{2}$ and Amalesh Dutta ${ }^{3}$ \\ ${ }^{1}$ Head, Department of Zoology, Kohima Science College, Kohima, Nagaland, India. \\ ${ }^{2}$ Professor, Department of Zoology, Cotton College, Guwahati, Assam 781001, India. \\ ${ }^{3}$ Professor, Department of Zoology, Gauhati University, Guwahati, Assam 781014, India.
}

\begin{abstract}
Food and feeding behaviour of Hyla annectans (Indian Hylid Frog) was studied in Nagaland over a period of three years. Specimens were collected during prebreeding, breeding and post-breeding periods. Highest volume of food intake was recorded in the post-breeding period and lowest in the pre-breeding period. In general the amount of food taken by the female was more than that of the male. The study will help in knowing the niche occupied by the species in the ecosystem and their distribution.
\end{abstract}

\section{Keywords \\ Amphibia, Hyla annectans, Indian Hylid Frog, feeding behaviour, Nagaland}

\section{Introduction}

Food and feeding behaviour of some Indian species of amphibia has been done by various workers. Studies on some of the important secies that devour agricultural pests that have been reported are Bufo melanostictus by Behura et al. (1960), and Srilatha et al. (1990), Bufo stomaticus by Battish et al. (1989), Amolops afghanus by Benny (1966), Limnonectes keralensis by Mallick and Mallick (1981), Euphlyctis cyanophlyctis by Sabins and Kolhatkar (1977) and Limnonectes limnocharis by Roy (1979).

The present investigation shows seasonal food preference of Hyla annectans which reflects the availability of prey items in different seasons in their prefered habitats. This species is found in temperate evergreen rain forest.

\section{Study area}

In Nagaland, the distribution of Hyla annectans is along the Borail Range at various altitudes ranging from $1400-2440 \mathrm{~m}$. Temperature of the habitat ranges from $4^{\circ} \mathrm{C}$ in winter (January) to $27^{\circ} \mathrm{C}$ in summer (July). Relative humidity is between 44 per cent in January to 92 per cent in July. Precipitation ranges are
$289-489 \mathrm{~mm}$ in July to $3-15 \mathrm{~mm}$ in January.

\section{Methodology}

Frogs were collected from March to November. Captured animals were killed and preserved in 5\% formaldehyde solution to check further digestion of the food materials. Snout-vent length and weight of the frog was recorded before dissecting out the stomach. The volume of the gut contents was measured by water displacement method in a graduated tube. Food items were identified with the help of a binocular microscope. Frequency of occurance of different food items was noted and percentage composition of different orders of insects was calculated. Altogether 63 males and 27 females were studied during the annual breeding cycle. Study of food spectrum was done at monthly intervals.

\section{Observation}

A total of 90 specimens collected during pre-breeding, breeding and post-breeding season have been studied to analyse the food spectrum. Body dimensions and food intake is presented in Table 1. Percentage composition of prey items have been presented in Table 2. Table 3 shows volume of food items in the stomach during different months of the year. Percentage of food items in the stomach during different breeding periods of annual breeding cycle have been presented in Table 4 .

Of the 90 frogs that were studied during the period of investigation, 26 stomachs were found to be empty. During December, January and February frogs hibernate and therefore were not collected. In general, the highest volume of food intake was recorded during post-breeding season and the lowest during pre-breeding season.

\section{Discussion}

Gut content analysis study on anurans by various workers have shown that food intake may vary in different seasons. In Hyla annectans volume of food intake was more in case of females than that of males throughout the year (Males $0.02-0.15 \mathrm{ml}$ and females 0.05-0.21ml). Johnson and Christiansen (1976) found 
Table 1. Body dimensions and volume of food intake in Hyla annectans.

\begin{tabular}{lllll}
\hline Period & Sex & SVL(mm) & $\begin{array}{l}\text { Body } \\
\text { weight }(\mathrm{g})\end{array}$ & $\begin{array}{l}\text { Food } \\
\text { Vol. (ml) }\end{array}$ \\
\hline Pre breeding & Male & $36-40$ & $3.65-4.12$ & 0.02 \\
& Female & $40-48$ & $6.9-8.0$ & $0.05-0.06$ \\
Breeding & Male & $37-41$ & $3.58-6.47$ & $0.04-0.1$ \\
& Female & $41-50$ & $8.31-11.86$ & $0.08-0.2$ \\
Postbreeding & Male & $37-41$ & $3.9-4.88$ & $0.03-0.15$ \\
& Female & $42-44$ & $6.4-7.2$ & $0.09-0.21$ \\
\hline
\end{tabular}

that food consumption was greater in larger frogs. Volume of food intake was found to increase with increase in body weight in Hyla annectans as in the case of amphibian body size to prey size reported by Mohanty-Hejmadi and Acharya (1982).

The food preference of Hyla annectans is varied. It is a terrestrial feeder as food items recorded are terrestrial. In most cases the gut contained only one type of food item showing its preference over the other s pecies present in the habitat. Arthropods form the bulk of the diet. Insects appear to be the most favoured food item. Coleopterans were found to be highest in terms of percentage composition $(21.41 \%)$. Of the identified orders of the class Insecta, Orthoptera, Isoptera, insect larvae and nymph, Diptera, Lepidoptera and Hymenoptera were recorded in order of preference. Arachnida (14.87\%) were also favoured whereas, Gastropoda comprised 2.47 per cent only.

Food intake is minimum during pre-breeding period. It increases during breeding period and post-breeding period. However, percentage composition varied in different seasons which depend more on the availability of food during these seasons rather than any particular preference. Labanick (1976) reported seasonal variation according to the availability of prey. During hibernation from December to February frogs are not sighted and hence were not collected.

The food spectrum obtained in the present investigation indicated that insects and spiders are the major food items of Hyla annectans. It must be noted that some of these insects are major pests of agricultural crops.

\section{References}

Bhattish, S.K., A. Agarwal and P. Singh (1989). Food Spectrum of marbled toad Bufo stomaticus Lutken. Journal of the Bombay Natural

Table 3. The volume of food intake ( $\mathrm{ml})$ in male and female Hyla annectans during different months.

\begin{tabular}{llllllllll}
\hline Sex & March & April & May & June & July & Aug. & Sept. & Oct. & Nov. \\
\hline Male & 0.02 & 0.02 & 0.04 & 0.05 & 0.1 & 0.15 & 0.11 & 0.10 & 0.03 \\
Female & 0.05 & 0.06 & 0.09 & 0.08 & 0.2 & 0.21 & 0.16 & 0.14 & 0.09 \\
\hline
\end{tabular}

Table 2. Percentage of occurrence of prey items in Hyla annectans in order of food preference.

\begin{tabular}{ll|ll}
\hline Food items & Composition & Food items & Composition \\
\hline Coleoptera & $21.41 \%$ & Diptera & $7.61 \%$ \\
Arachnida & $14.87 \%$ & Lepidoptera & $7.04 \%$ \\
Orthoptera & $12.04 \%$ & Hymenoptera & $3.57 \%$ \\
Isoptera & $12.26 \%$ & Gastropoda & $2.47 \%$ \\
Insect larvae/nymphs & $11.76 \%$ & & \\
\hline
\end{tabular}

History Society 86: 22-31.

Behura, B.K., P.K. Mohanty and G.S. Ghosh (1960). On the diet and the feeding habits of the common toad Bufo melanostictus. Proceedings of Indian Science Congress 4793: 480-481.

Benny, P.Y. (1996). The food and feeding habits of the torrent frog. Amolops larutensis. Journal of Zoology 149: 204-214.

Jerdon, T.C. (1870). Notes on Indian herpetology. Proceedings of the Asiatic Society of Bengal 2: 66-85.

Johnson, B.K. and J.L.Christiansen (1976). The food and food habits of Blanchard's Cricket frog, Acris crepitans Blenchardi (Amphibia: Anura:Hylidae) Iowa. Journal of Herpetology 10(2): 63-74.

Labanick,G.M. (1976). Prey availability, consumption and selection in cricket frog, Acris crepitans (Amphibia: Anura: Hylidae). Journal of Herpetology 10(4): 293-298.

Mallick, P.K. and S.C. Mallick (1981). Notes on food and feeding habits of six Rana verucosa Gunther. Science and Culture, India 47(110): 403-404.

Mohanty-Hejmadi, P. and B.K. Acharya (1982). Observations on food habits of six species of Indian frogs. Journal of the Bombay Natural History Society 79: 120-124.

Roy, D. (1979) . Studies on certain aspects of ecology and development of Rana limnocharis Weigmann. Ph.D. Thesis, N.E.H.U. Shilllong, India. Sabins, J.H. and B.I. Kolhatkar (1977). Observation on the food preference of Rana cyanophlyctis C Schn. Comparitive Physiology and Ecology 2(40): 232-233.

Sreelatha, K.S., P. Natarajan and S.D. Ritakumari (1990). Studies on the food and feeding behaviour of Bufo melanostictus. Journal of Ecobiology 2(3): 213-221.

Table 4. Percentage of food items in the stomach of Hyla annectans during different breeding seasons.

\begin{tabular}{llll}
\hline Prey items & \multicolumn{3}{c}{ Percentage composition (\%) } \\
& $\begin{array}{l}\text { Pre-breeding } \\
\text { period }\end{array}$ & $\begin{array}{l}\text { Breeding } \\
\text { period }\end{array}$ & $\begin{array}{l}\text { Post-breeding } \\
\text { period }\end{array}$ \\
\hline Coleoptera & 20.72 & 26.0 & 18.35 \\
Arachnida & 14.08 & 5.41 & 22.40 \\
Orthoptera & Nil & 10.38 & 19.33 \\
Isoptera & 21.8 & 15.73 & 4.91 \\
Diptera & 7.02 & 13.32 & 3.79 \\
Lepidoptera & Nil & 5.68 & 11.6 \\
Hymenoptera & 2.52 & 16.66 & 1.83 \\
Hemiptera & 7.01 & Nil & 4.55 \\
Insectlarvae/nymphs & 15.66 & 7.33 & 13.16 \\
Gastropoda & 11.16 & Nil & Nil \\
\hline
\end{tabular}

